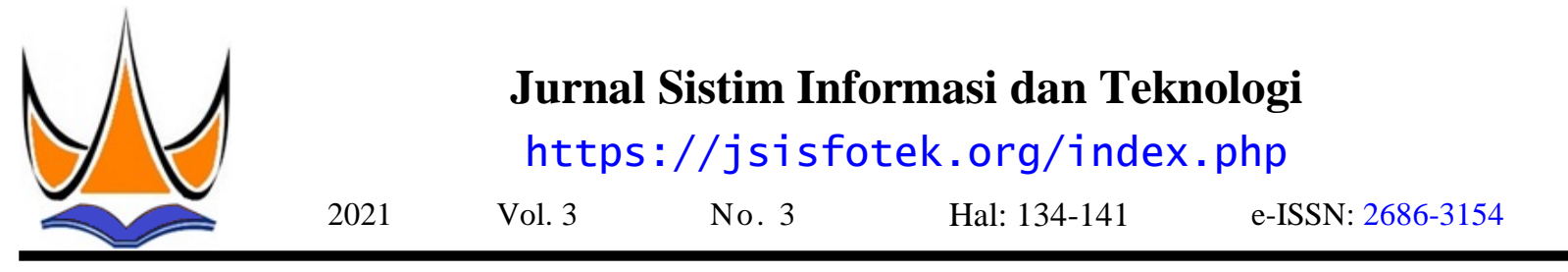

\title{
Sistem Pendukung Keputusan bagi Penerima Bantuan Komite Sekolah Menggunakan Metode Topsis
}

\author{
Suci Mardayatmi ${ }^{1 凶}$ Sarjon Defit $^{2}$, Gunadi Widi Nurcahyo ${ }^{3}$ \\ ${ }^{1}$ Sekolah Menengah Kejuruan Negeri 3 Muko-muko \\ ${ }^{2,3}$ Universitas Putra Indonesi YPTK Padang \\ aciemar@gmai1.com
}

\begin{abstract}
Vocational High School Number 3 Mukomuko was the school that has given assistance for the learners. It was by exempting learners from paying committee charge monthly, it called Bantuan Komite Sekolah (BKS). In order to give motivation for the learners who was unfortunate to keep staying at the school, so it can make the learners to keep going on teaching and learning process $(\mathrm{KBM})$. This research used Topsis method by collecting data for the prospective scholarship learners as many as 20 learners by categorizes were parents' revenue, the total numbers of duties, the distance of residence, the average score of report and the condition of living environment. The result of try out from 20 learners who was obtain BKS by using Topsis Method showed that there were 18 learners who were significant to obtain scholarship by validity score was $90 \%$. It was be a sample, before Topsis Method was used and the data was reliable after using Topsis Method. The development of supporting decision application system used Topsis Method that was getting in more accurated qualification. Futhermore, this system can help the school in constructing decisions to get the result be more advantageous in determining for the next BKS recipients.
\end{abstract}

Keywords: Supporting Decision System, Recipients of Assistance, Scholarship, School Committee, Topsis.

\begin{abstract}
Abstrak
SMK Negeri 3 Muko muko merupakan sekolah yang memberikan bantuan kepada siswa yang tidak mampu. Dengan cara membebaskan siswa dalam membayar iuran komite perbulannya, yang disebut dengan Bantuan Komite Sekolah (BKS). Agar memotivasi siswa yang tidak mampu tetap sekolah, sehingga siswa tetap dapat merasakan Kegiatan Belajar Mengajar (KBM). Dalam penelitian ini menggunakan metode Topsis dengan data calon penerima beasiswa sebanyak 20 orang dengan kriteria yaitu penghasilan orang tua, jumlah tanggungan, jarak tempat tinggal, nilai rata-rata Raport dan kondisi tempat tinggal. Dari hasil uji coba terhadap penerima BKS dengan data pendaftar sejumlah 20 orang siswa, menggunakan Metode Topsis diperoleh jumlah yang layak menerima beasiswa sebanyak 18 orang siswa dengan tingkat akurasi yang diperoleh yaitu $90 \%$ yang diperoleh dari data sampel saat belum menggunakan metode Topsis dan data yang sesuai setelah menggunakan metode Topsis. Pengembangan aplikasi Sistem pendukung keputusan menggunakan metode Topsis, menghasilkan kualifikasi yang lebih akurat.Sehingga sistem ini dapat membantu pihak Sekolah dalam mengambil keputusan agar hasil yang diperoleh lebih optimal dalam penentuan Pemberian BKS berikutnya.
\end{abstract}

Kata kunci: Sistem Pendukung Keputusan, Penerima bantuan, Beasiswa, Komite sekolah, Topsis.

(c) 2021 JSisfotek

\section{Pendahuluan}

Sistem Pendukung Keputusan (SPK) atau Decision Support System (DSS) merupakan sistem berbasis komputer yang terdiri dari tiga komponen yang saling berhubungan [1].Komponen tersebut terdiri atas sistem informasi interaktif yang menyediakan informasi, pemodelan, dan manipulasi data [2]. Pengambilan keputusan dengan berbagai kriteria dianggap sebagai alat pengambilan keputusan canggih yang melibatkan faktor kuantitatif dan kualitatif [3]. SPK diperlukan untuk membakukan proses pengambilan keputusan agar menjadi lebih kompleks [4].

SPK dapat memaksimalkan pengambilan keputusan untuk siswa yang berhak menerima beasiswa tersebut dan juga dapat mempermudah petugas di dalam memberikan penilaian terhadap calon siswa penerima beasiswa, dengan adanya sistem ini dapat menyeleksi secara detail siswa yang menerima beasiswa adalah siswa yang benar benar pantas menerima beasiswa dan di dalam pemrosesan penyeleksian dapat lebih cepat [5].

Metode menjadi alat penting bagi manajer organisasi publik atau swasta untuk membuat keputusan bersifat dinamis, pembuat keputusan harus yakin bahwa proses analisis dilakukan dengan baik dan menyeluruh untuk memperkirakan hasil yang potensial dari keputusannya [6]. The Technique for Order of Preference by Similarity to Ideal Solution (TOPSIS) merupakan solusi ideal positif yang terdiri dari skor terbaik di semua kriteria [7]. Alternatif yang paling diinginkan tidak hanya terbaik dari solusi ideal positif tetapi skor terbaik dapat juga solusi ideal negatif [8]. TOPSIS

Diterima: 12-03-2021 | Revisi: 15-04-2021 | Diterbitkan: 30-09-2021 | DOI: 10.37034/jsisfotek.v3i3.56 
secara praktis digunakan untuk menyelesaikan pemecahan masalah yang akan dihadapi. Adapun pengambilan keputusan [9]. Dan mudah digunakan kerangka kerja yang ada pada penelitian ini dapat dikarenakan penggunaannya yang sangat sederhana dilihat pada Gambar 1.

[10], solusi optimal dalam metode Topsis adalah dengan menentukan kedekatan relatif suatu alternatif dengan terhadap solusi idela posisitf [11] sehingga dapat menyeleksi secara detail siswa yang pantas menerima beasiswa dan proses penyeleksian lebih cepat.

SMK Negeri 3 Muko muko merupakan salah satu SMK yang berada di kabupaten Mukomuko. Kabupaten Muko muko terletak di Pantai Barat Pulau Sumatera dan berbatasan langsung dengan Samudera Hindia [12]. Dengan letak geografis yang strategis, sehingga menjadikan sekolah ini diminati oleh siswa dan siswi baik yang berasal dari Sumatera Barat maupun Provinsi Bengkulu. Proses kegiatan belajar mengajar sering menjadi hambatan dikarenakan banyaknya siswa yang bekerja diwaktu jam sekolah. Untuk memperlancar proses belajar mengajar, maka pemerintah memberikan bantuan berupa beasiswa. Dalam pembagian beasiswa yang diberikan pemerintah, seringkali terjadi pertengkaran dikarena tidak akuratnya data yang ada, pemerintah hanya menarik data yang berasal dari data Dapodik untuk memberikan beasiswa kepada siswa, sehingga dengan adanya permasalahan ini pihak sekolah mengambil keputusan untuk memberikan bantuan kepada siswanya melalui komite sekolah. Proses seleksi beasiswa merupakan masalah yang sangat kompleks [13].

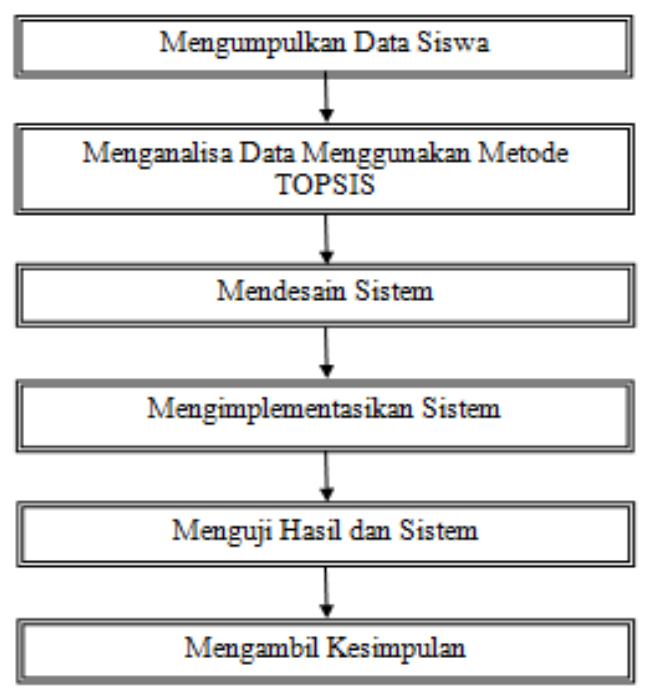

Gambar 1. Kerangka Kerja Penelitian

Komite sekolah yang diatur dalam Permendikbud Nomor 75 Tahun 2016 [14], merupakan lembaga mandiri yang beranggotakan orang tua / wali siswa, komunitas sekolah, dan tokoh masyarakat yang peduli terhadap pendidikan. Dalam pemberian Bantuan Komite Sekolah (BKS), secara khusus komite berfungsi memberikan saran-saran untuk proses belajar mengajar, meningkatkan kualitas lulusan, dan meningkatkan mutu sekolah [15].

\section{Metodologi Penelitian}

Metodologi penelitian bertujuan untuk memberikan kerangka penelitian yang sistematis dan keseluruhan metode, prosedur, konsep kerja dan aturan yang digunakan dalam penelitian, sehingga dapat memberikan kesesuaian antara tujuan penelitian dengan karakteristik permasalahan, serta dapat meminimasi kesalahan-kesalahan yang mungkin terjadi serta 2.2.1 Membuat matriks keputusan yang ternormalisasi mendapatkan hasil penelitian yang sesuai dengan $\mathrm{V}$ tujuan yang telah ditetapkan. Penelitian dilakukan di SMK Negeri 3 Muko muko, merupakan Sekolah Menengah Kejuruan yang berlokasi di Jl. Lintas Sumatera - Barat Kec. XIV Koto kabupaten Muko muko, Provinsi Bengkulu.

Kerangka kerja penelitian merupakan kumpulan konsep yang tersusun secara sistematis agar penelitian yang dilakukan menjadi lebih baik. Kerangka kerja dibuat agar tahapan-tahapan tersebut lebih mudah dipahami

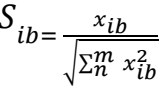

Yang mana nilai $\mathrm{S}$ merupakan elemen dari matriks keputusan yang ternormalisasi $\mathrm{R}$ dan $\mathrm{X}$ elemen matrik keputusan $\mathrm{x}$.

2.2.2 Membuat matriks keputusan yang dan dapat diterima oleh semua pihak selama melakukan penelitian dan akan menjadi pedoman dalam 
Dengan bobot $O_{i \mathrm{~b}}=\left(O_{1}, O_{2}, O_{3}, \ldots, O_{n}\right)$, dimana Tahap mengimplementasi sistem merupakan tahapan $O_{i b}$ adalah bobot dari kriteria ke -b maka normalisasi penerapan dari proses mendesain sistem, yaitu dengan bobot matriks $K$ adalah :

$K_{i b}=O_{i b} S_{i b}$ mengambil data kriteria siswa penerima beasiswa pada

metode TOPSIS. pada tahapan sebelumnya di mana Yang mana Kmerupakan elemen dari matriks data akan diproses, kemudian sistem berjalan sesuai keputusan yang ternormalisasi terbobot $K$ dan $O$ adalah dengan yang diharapkan. Implementasi ini dilakukan bobot dari kriteria ke -b, sedangkan Smerupakan untuk membandingkan hasil yang didapatkan elemen dari matriks keputusan yang ternormalisasi.

2.2.3 Menentukan matriks solusi ideal positif dan solusi ideal negatif

menggunakan metode secara manual dan menggunakan metode dengan sistem.

Solusi ideal positif dinotasikan $Z^{+}$, sedangkan solusi ideal negatif dinotasikan $Z^{-}$dengan persamaan :

a. $Z^{+}=\left\{\left(\max K_{i b} \mid b \in B\right),\left(\min K_{i b} \mid b \in B^{\prime}\right)\right\}$

\subsection{Menguji Sistem}

b. $Z^{-}=\left\{\left(\min K_{i b} \mid b \in B\right),\left(\max K_{i b} \mid b \in B^{\prime}\right)\right\}$

(4) Setelah implementasi sistem dilakukan, maka pada Yang mana $Z_{b}^{+}$adalah elemen matriks solusi ideal tahap ini dilakukan uji coba terhadap aplikasi tersebut positif dan $Z_{b}^{-}$adalah elemen matriks solusi ideal negatif.

\subsubsection{Menghitung Separasi}

a. $P^{+}$adalah jarak alternatif dari solusi ideal positif didefinisikan sebagai:

Analisa Sistem merupakan suatu kegiatan yang dilakukan dengan tujuan untuk mengetahui permasalahan serta kendala yang sering terjadi pada sistem untuk dapat dilakukan perbaikan [17].

$P_{i}^{-}=\sqrt{\sum_{b=1}^{n}\left(K_{i b}-Z_{b}^{-}\right)^{2}}$

b. $P^{-}$adalah jarak alternatif dari solusi ideal negatif didefinisikan sebagai:

$P_{i}^{+}=\sqrt{\sum_{b=1}^{n}\left(K_{i b}-Z_{b}^{+}\right)^{2}}(6)$ sehingga analisis hasil implementasi dari pengujian yang dilakukan baik secara manual maupun aplikasi dengan menggunakan metode TOPSIS berdasarkan kriteria yang telah ditentukan menghasilkan tingkat akurasi yang tepat.

\subsection{Mengambil Kesimpulan}

Mengambil kesimpulan berdasarkan literatur dan pembahasan permasalahan yang ada merupakan bagian terakhir dari penelitan. Kesimpulan akan diambil berdasarkan hasil analisis dari penelitian, sehingga dapat diambil kesimpulan layak atau tidak layaknya siswa yang menjadi penerima Beasiswa Komite

2.2.5 Menghitung keadaan relatif terhadap solusi ideal Sekolah di SMK Negeri 3 Mukomuko. positif

Dapat dihitung dengan menggunakan persamaan sebagai berikut :

$U_{i}^{+}=\frac{C_{i}^{-}}{\left(C_{i}^{-}+C_{i}^{+}\right)}, 0 \leq C_{i}^{+} \leq 1$

\subsubsection{Meranking alternatif}

Alternatif diurutkan dari nilai $E^{+}$terbesar ke nilai terkecil dan yang menjadi Alternatif dengan nilai $E^{+}$ terbesar merupakan solusi yang terbaik.

\subsection{Mendesain Sistem}

Mendesain sistem akan membahas tentang rancangan model dari sistem dengan menentukan kriteria siswa yang akan menerima beasiswa di SMK Negeri 3 Mukomuko berdasarkan data yang ada. Data tersebut adalah :

\section{a. Menentukan Kriteria.}

Data yang dibutuhkan untuk menetukan kriteria adalah penghasilan orang tua, jumlah tanggungan orang tua,
jarak tempat tinggal, nilai rata-rata raport, dan kondisi tempat tinggal siswa.

b. Mengolah data berdasarkan kriteria yang ditentukan sebelumnya.

\subsection{Mengimplementasikan Sistem}

\section{Hasil dan Pembahasan}

Analisa sistem dibuat berdasarkan data-data siswa dengan kriteria yang ditentukan dengan menggunakan

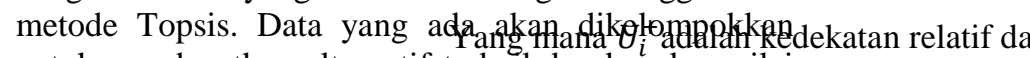
untuk mendapatkan alternatif terbaik berdasarkan nilai preferensi yang diberikan. Arsitektur analisa sistem seperti pada Gambar 2.

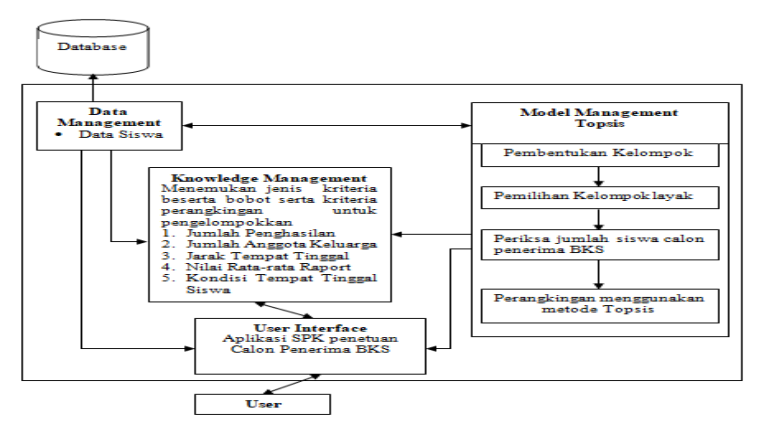

Gambar 2. Arsitektur Analisa Sistem

\subsection{Data}

Data yang digunakan dalam penelitian ini adalah data siswa calon penerima beasiswa SMK Negeri 3 Muko muko kelas $X$ berjumlah sebanyak 20 orang siswa. Data diambil dari guru bimbingan konsling dengan mendapatkan izin dari kepala sekolah. Data ini akan digunakan sebagai pedoman untuk menentukan kriteria penerima beasiswa. Adapun data yang akan dijadikan 
kriteria sebagai penentu layak atau tidak layaknya penerima BKS adalah jumlah penghasilan, jumlah anggota keluarga, jarak tempat tinggal, nilai rata-rata raport dan kondisi tempat tinggal siswa.

Tabel 1. Data Siswa Calon Penerima Beasiswa SMK Negeri 3 Muko muko

\begin{tabular}{|c|c|c|c|c|c|c|}
\hline No & Nama Siswa & $\begin{array}{c}\text { Jumlah } \\
\text { Penghasilan } \\
\text { (Rp) }\end{array}$ & $\begin{array}{c}\text { Jumlah } \\
\text { Anggota } \\
\text { Keluarga }\end{array}$ & $\begin{array}{c}\text { Jarak } \\
\text { Tempat } \\
\text { Tinggal } \\
(\mathrm{Km}) \\
\end{array}$ & $\begin{array}{c}\text { Nilai } \\
\text { Rata-rata } \\
\text { Raport }\end{array}$ & $\begin{array}{c}\text { Tempat Tinggal } \\
\text { Siswa }\end{array}$ \\
\hline 1. & Mesaki & 750.000 & 5 & 3 & 76,25 & Rumah Orangtua \\
\hline & Rafni Novina & 350.000 & 3 & 18 & 84,29 & Rumah Orangtua \\
\hline & Ana Maryana & 250.000 & 6 & 18 & 80,77 & Rumah Orangtua \\
\hline & Chintia Nopriyanti & 1.000 .000 & 4 & 0.5 & 80,50 & Rumah Orangtua \\
\hline & Jendry Apriyanto & 500.000 & 6 & 9 & 81,13 & Rumah Orangtua \\
\hline & Joka Amara & 400.000 & 4 & 18 & 76,90 & Rumah Orangtua \\
\hline 7. & Eka Puspita Sari & 750.000 & 4 & 5 & 78,84 & Rumah Orangtua \\
\hline & Aditya Warman & 750.000 & 5 & 0.2 & 73,47 & Rumah Orangtua \\
\hline & Ade Hamdan Lesmana & 900.000 & 5 & 0.3 & 80,64 & Rumah Orangtua \\
\hline 10. & Artika Yuri & 1.000 .000 & 7 & 12 & 76,81 & Rumah Orangtua \\
\hline 11. & Vita loka & 1.000 .000 & 4 & 7 & 77,06 & Rumah Orangtua \\
\hline 12. & Sherli & 500.000 & 3 & 18 & 84,69 & Rumah Orangtua \\
\hline 13. & Meci Sepni Monicha & 500.000 & 4 & 18 & 76,67 & Rumah Orangtua \\
\hline 14. & Nola Novita Sari & 750.000 & 5 & 21 & 82,54 & Rumah Orangtua \\
\hline 15. & Ari Uman Mu'isan & 500.000 & 5 & 15 & 83,08 & Tempat Kakak \\
\hline 16. & Anila Apriani & 800.000 & 4 & 18 & 85,94 & Rumah Orangtua \\
\hline 17. & Saras Parwati & 1.000 .000 & 5 & 7 & 86,81 & Rumah Orangtua \\
\hline 18. & Dewi Kartika & 1.000 .000 & 8 & 18 & 87,88 & Rumah Orangtua \\
\hline 19. & Agus Triyanto & 1.000 .000 & 6 & 0.6 & 87,00 & Rumah Orangtua \\
\hline 20. & Sepriyanto & 800.000 & 7 & 17 & 73,97 & Rumah Orang tua \\
\hline
\end{tabular}

Tabel 1 menjelaskan data siswa SMK Negeri 3 Muko muko yang digunakan dalam penelitian.

Tabel 2. Kriteria Pertimbangan

\begin{tabular}{ll}
\hline Kriteria & Keterangan \\
\hline S1 & Jumlah Penghasilan Orangtua \\
S2 & Jumlah Tanggungan Orangtua \\
S3 & Jarak Tempat Tinggal \\
S4 & Nilai Rata-rata Rapor Semester \\
S5 & Kondisi Tempat Tinggal \\
\hline
\end{tabular}

Proses dan kriteria penilaian yang diperhitungkan dalam menentukan penerima beasiswa pada SMK Negeri 3 Muko muko dengan menggunakan metode Topsis. Adapun data yang akan dijadikan kriteria sebagai penentu layak atau tidak layaknya penerima BKS adalah jumlah penghasilan orang tua, jumlah tanggungan orang tua, jarak tempat tinggal, nilai ratarata raport dan kondisi tempat tinggal siswa.

Tabel 3. Tingkat kepentingan dari tiap kriteria

\begin{tabular}{ll}
\hline Kepentingan & Nilai \\
\hline Sangat rendah & 1 \\
Rendah & 2 \\
Cukup & 3 \\
Tinggi & 4 \\
Sangat Tinggi & 5 \\
\hline
\end{tabular}

Keluaran yang dihasilkan dari penelitian ini adalah sebuah alternatif yang memiliki nilai tertinggi dibandingkan dengan alternatif nilai yang lain. Pada penelitian ini hasil keluarannya diambil dari urutan alternatif tertinggi ke alternatif terendah.Hasil akhir yang dikeluarkan oleh program nanti berasal dari nilai setiap kriteria, karena dalam setiap kriteria memiliki nilai yang berbeda-beda.

Tabel 4. Nilai Kriteria dan Bobot

\begin{tabular}{cclc}
\hline $\begin{array}{c}\text { Kode } \\
\text { Kriteria }\end{array}$ & Bobot & \multicolumn{1}{c}{ Range } & Nilai \\
\hline S1 & 3 & $\leq$ Rp 500.000 & 1 \\
& & Rp 500.000-Rp 700.000 & 2 \\
& & $\geq \operatorname{Rp~700.000~}$ & 3 \\
S2 & 4 & $\geq 5$ & 3 \\
& & $5-3$ & 2 \\
& & $3-2$ & 1 \\
& & $\leq 1$ & 0 \\
S3 & 3 & $>10$ & 3 \\
& & $5-10$ & 2 \\
& & $<5$ & 1 \\
S4 & 5 & $0-30$ & 1 \\
& & $31-50$ & 2 \\
& & $51-65$ & 3 \\
& & $66-75$ & 4 \\
& & $76-100$ & 5 \\
S5 & 3 & Rumah Orangtua & 3 \\
& & Kos/Asrama & 2 \\
& & Rumah Pribadi & 1 \\
\hline
\end{tabular}

Pengambil keputusan memberikan bobot preferensi untuk masing-masing kriteria, berdasarkan data siswa yang diperoleh dari SMK Negeri 3 Muko muko, dapat kita bentuk sebuah rating kecocokan dari setiap alternatif pada setiap kriteria. 
b. Ternormalisasi Kategori $\mathrm{S} 2=$ jumlah tanggungan orang tua

$$
\begin{gathered}
x 2=\sqrt{\begin{array}{c}
\left(3^{2}+2^{2}+3^{2}+2^{2}+3^{2}+2^{2}+2^{2}+2^{2}+\right. \\
2^{2}++3^{2}+2^{2}+2^{2}+2^{2}+2^{2}+ \\
\left.2^{2}+2^{2}+2^{2}+3^{2}+3^{2}+3^{2}\right)
\end{array}} \\
x 2=10,72381 \\
S_{A 1 S 2}=\frac{3}{10,72381}=0,27975 \\
S_{A 2 S 2}=\frac{2}{10,72381}=0,18650 \\
S_{A 3 S 2}=\frac{3}{10,72381}=0,27975 \\
S_{A 4 S 2}=\frac{2}{10,72381}=0,18650 \\
S_{A 5 S 2}=\frac{3}{10,72381}=0,27975
\end{gathered}
$$

Tabel 5. Pembobotan

\begin{tabular}{lrrrrr}
\hline Alternatif & S1 & S2 & S3 & S4 & S5 \\
\hline Mesaki & 3 & 3 & 1 & 5 & 3 \\
Rafni Novina & 1 & 2 & 3 & 5 & 3 \\
Ana Maryana & 1 & 3 & 3 & 5 & 3 \\
Chintia Nopriyanti & 3 & 2 & 1 & 5 & 3 \\
Jendry Apriyanto & 2 & 3 & 2 & 5 & 3 \\
Joka Amara & 1 & 2 & 3 & 5 & 3 \\
Eka Puspita Sari & 3 & 2 & 2 & 5 & 3 \\
Aditya Warman & 3 & 2 & 1 & 4 & 3 \\
Ade Hamdan Lesmana & 3 & 2 & 1 & 5 & 3 \\
Artika Yuri & 3 & 3 & 3 & 5 & 3 \\
Vita loka & 3 & 2 & 2 & 5 & 3 \\
Sherli & 2 & 2 & 3 & 5 & 3 \\
Meci Sepni Monicha & 2 & 2 & 3 & 5 & 3 \\
Nola Novita Sari & 3 & 2 & 3 & 5 & 3 \\
Ari Uman Mu'isan & 2 & 2 & 3 & 5 & 3 \\
Anila Apriani & 3 & 2 & 3 & 5 & 3 \\
Saras Parwati & 3 & 2 & 2 & 5 & 3 \\
Dewi Kartika & 3 & 3 & 3 & 5 & 3 \\
Agus Triyanto & 3 & 3 & 1 & 5 & 3 \\
Sepriyanto & 3 & 3 & 3 & 4 & 3 \\
\hline
\end{tabular}

Setelah menentukan kriteria, bobot dan range maka tahap selanjutnya menghitung pembobotan, dan mendapatkan nilai dari pembobotan, maka langkah selanjutnya adalah menentukan matriks keputusan ternormalisasi dapat dilihat pada penyelesaian berikut :

3.2 Membuat matriks keputusan yang ternormalisasi

a. Ternormalisasi Kategori $\mathrm{S} 1=$ jumlah penghasilan orang tua

$$
\begin{gathered}
S_{i b}=\frac{x_{i b}}{\sqrt{\sum_{n}^{m} x_{i b}^{2}}} \\
x 1=\sqrt{\begin{array}{l}
\left(3^{2}+1^{2}+1^{2}+3^{2}+2^{2}+1^{2}+3^{2}+\right. \\
3^{2}+3^{2}+3^{2}+3^{2}+2^{2}+2^{2}+3^{2}+ \\
\left.2^{2}+3^{2}+3^{2}+3^{2}+3^{2}+3^{2}\right)
\end{array}} \\
x 1=11,66190 \\
S_{A 1 S 1}=\frac{3}{11,66190}=0,25725 \\
S_{A 2 S 1}=\frac{1}{11,66190}=0,08575 \\
S_{A 3 S 1}=\frac{1}{11,66190}=0,08575 \\
S_{A 4 S 1}=\frac{3}{11,66190}=0,25725 \\
S_{A 5 S 1}=\frac{2}{11,66190}=0,17150
\end{gathered}
$$

c. Ternormalisasi Kategori S3 = jarak tempat tinggal

$$
\begin{aligned}
& x 3=\sqrt{\begin{array}{r}
\left(1^{2}+3^{2}+3^{2}+1^{2}+2^{2}+3^{2}+2^{2}+\right. \\
1^{2}+1^{2}+3^{2}+2^{2}+3^{2}+3^{2}+3^{2}+3^{2}+ \\
\left.3^{2}+2^{2}+3^{2}+1^{2}+3^{2}\right)
\end{array}} \\
& x 3=10,95450 \\
& S_{A 1 S 3}=\frac{1}{10,95450}=0,09129 \\
& S_{A 2 S 3}=\frac{3}{10,95450}=0,27386 \\
& S_{A 3 S 3}=\frac{3}{10,95450}=0,27386 \\
& S_{A 4 S 3}=\frac{1}{10,95450}=0,09129 \\
& S_{A 5 S 3}=\frac{2}{10,95450}=0,18257
\end{aligned}
$$

d. Ternormalisasi Kategori S4 = Nilai Rata-rata Raport

$$
\begin{gathered}
x 4=\sqrt{\begin{array}{c}
\left(5^{2}+5^{2}+5^{2}+5^{2}+5^{2}+5^{2}+5^{2}+\right. \\
4^{2}+5^{2}+5^{2}+5^{2}+5^{2}+5^{2}+5^{2}+ \\
\left.5^{2}+5^{2}+5^{2}+5^{2}+5^{2}+4^{2}\right)
\end{array}} \\
x 4=21,95450 \\
S_{A 1 S 4}=\frac{5}{21,95450}=0,22774 \\
S_{A 8 S 4}=\frac{4}{21,95450}=0,18219
\end{gathered}
$$

e. Ternormalisasi Kategori S5 = Kondisi Tempat Tinggal Siswa 


$$
x 5=\sqrt{\begin{array}{c}
\left(3^{2}+3^{2}+3^{2}+3^{2}+3^{2}+3^{2}+3^{2}+\right. \\
3^{2}+3^{2}+3^{2}+3^{2}+3^{2}+3^{2}+3^{2}+ \\
\left.3^{2}+3^{2}+3^{2}+3^{2}+3^{2}+3^{2}\right)
\end{array}}
$$$$
x 5=13,41640
$$

$$
S_{A 1 S 5}=\frac{3}{13,41640}=0,22361
$$

3.2 Membuat matrikskeputusan yang ternormalisasi terbobot

$$
K_{i b}=O_{i b} S_{i b}
$$

a. Ternormalisasi terbobot Kategori $\mathrm{S} 1=3$

$$
\begin{aligned}
& K_{O 1 S 1}=3 * 0,25725=0,77174 \\
& K_{O 2 S 1}=3 * 0,08575=0,25725
\end{aligned}
$$

b. Ternormalisasi terbobot Kategori $\mathrm{S} 2=4$

$$
\begin{gathered}
K_{O 1 S 2}=4 * 0,27975=1,11901 \\
K_{O 2 S 2}=4 * 0,18650=0,7460
\end{gathered}
$$

c. Ternormalisasi terbobot Kategori S3 $=3$

$$
\begin{aligned}
& K_{O 1 S 3}=3 * 0,09129=0,27386 \\
& K_{O 2 S 3}=3 * 0,27386=0,82158
\end{aligned}
$$

d. Ternormalisasi terbobot Kategori $\mathrm{S} 4=5$

$$
\begin{aligned}
& K_{O 1 S 4}=5 * 0,22774=1,13872 \\
& K_{O 8 S 4}=5 * 0,18219=0,91097
\end{aligned}
$$

e. Ternormalisasi terbobot Kategori S5 $=3$

$$
K_{O 1 S 5}=3 * 0,22361=0,67082
$$

Tabel 6. Normalisasi Terbobot

\begin{tabular}{lccccc}
\hline Alternatif & S1 & S2 & S3 & S4 & S5 \\
\hline Mesaki & 0,77174 & 1,11901 & 0,27386 & 1,13872 & 0,67082 \\
Rafni Novina & 0,25725 & 0,74600 & 0,82158 & 1,13872 & 0,67082 \\
Ana Maryana & 0,25725 & 1,11901 & 0,82158 & 1,13872 & 0,67082 \\
Chintia Nopriyanti & 0,77174 & 0,74600 & 0,27386 & 1,13872 & 0,67082 \\
Jendry Apriyanto & 0,51450 & 1,11901 & 0,54772 & 1,13872 & 0,67082 \\
Joka Amara & 0,25725 & 0,74600 & 0,82158 & 1,13872 & 0,67082 \\
Eka Puspita Sari & 0,77174 & 0,74600 & 0,54772 & 1,13872 & 0,67082 \\
Aditya Warman & 0,77174 & 0,74600 & 0,27386 & 0,91097 & 0,67082 \\
Ade Hamdan Lesmana & 0,77174 & 0,74600 & 0,27386 & 1,13872 & 0,67082 \\
Artika Yuri & 0,77174 & 1,11901 & 0,82158 & 1,13872 & 0,67082 \\
Vita loka & 0,77174 & 0,74600 & 0,54772 & 1,13872 & 0,67082 \\
Sherli & 0,51450 & 0,74600 & 0,82158 & 1,13872 & 0,67082 \\
Meci Sepni Monicha & 0,51450 & 0,74600 & 0,82158 & 1,13872 & 0,67082 \\
Nola Novita Sari & 0,77174 & 0,74600 & 0,82158 & 1,13872 & 0,67082 \\
Ari Uman Mu'isan & 0,51450 & 0,74600 & 0,82158 & 1,13872 & 0,67082 \\
Anila Apriani & 0,77174 & 0,74600 & 0,82158 & 1,13872 & 0,67082 \\
Saras Parwati & 0,77174 & 0,74600 & 0,54772 & 1,13872 & 0,67082 \\
Dewi Kartika & 0,77174 & 1,11901 & 0,82158 & 1,13872 & 0,67082 \\
Agus Triyanto & 0,77174 & 1,11901 & 0,27386 & 1,13872 & 0,67082 \\
Sepriyanto & 0,77174 & 1,11901 & 0,82158 & 0,91097 & 0,67082 \\
\hline
\end{tabular}

3.3 Menentukan matrik solusi ideal positif dan solusi $(\max 0,77174 ; 0,25725 ; 0,2572 ; 0,77174 ; 0,51450$; ideal negatif

0,$2572 ; 0,77174 ; 0,77174 ; 0,77174 ; 0,77174 ; 0,77174$ 0,$51450 ; 0,51450 ; \quad 0,77174 ; 0,51450 ; \quad 0,77174$ Berikut menentukan solusi ideal positif $\left(Z^{+}\right)$dan solusi 0,$\left.\left.77174 ; 0,77174 ; 0,77174 ; 0,77174\right)\right\}$ ideal negatif $\left(Z^{-}\right)$dapat dilihat pada : $=0,77174$

a. $Z^{+}=\left\{\left(\max K_{i b} \mid b \in B\right),\left(\min K_{i b} \mid b \in B^{\prime}\right)\right.$

$=\{(\max 0,77174 ; 0,25725 ; 0,2572 ; 0,77174 ; 0,51450$; 0,$2572 ; 0,77174 ; 0,77174 ; 0,77174 ; 0,77174 ; 0,77174$; 0,$51450 ; \quad 0,51450 ; \quad 0,77174 ; 0,51450 ; \quad 0,77174$; $0,77174 ; 0,77174 ; 0,77174 ; 0,77174)$

Tabel7. Solusi Ideal Positif dan Solusi Ideal Negatif

\begin{tabular}{llllll}
\hline $\begin{array}{l}\text { Solusi } \\
\text { ideal }\end{array}$ & S1 & S2 & S3 & S4 & S5 \\
\hline Positif & 0,25725 & 1,11901 & 0,27386 & 1,13872 & 0,67082 \\
Negatif & 0,77174 & 0,74600 & 0,82158 & 0,91097 & 0,67082
\end{tabular}

$(\min 0,77174 ; 0,25725 ; 0,2572 ; 0,77174 ; 0,51450$; 0,$2572 ; 0,77174 ; 0,77174 ; 0,77174 ; 0,77174 ; 0,77174$; 0,$51450 ; 0,51450 ; \quad 0,77174 ; 0,51450 ; \quad 0,77174 ;$ Langkah selanjutnya setelah didapat hasil dari solusi $0,77174 ; 0,77174 ; 0,77174 ; 0,77174)\}$

$=0,25725$

b. $Z^{-}=\left\{\left(\min K_{i b} \mid b \in B\right),\left(\max K_{i b} \mid b \in B^{\prime}\right)\right.$

$=\{(\min 0,77174 ; 0,25725 ; 0,2572 ; 0,77174 ; 0,51450$; ideal positif dan solusi ideal negatif adalah menghitung separasi

\subsection{Menghitung separasi}

Menentukan jarak alternatif antara nilai matriks solusi 0,$2572 ; 0,77174 ; 0,77174 ; 0,77174 ; 0,77174 ; 0,77174$; 0,$51450 ; \quad 0,51450 ; \quad 0,77174 ; 0,51450 ; \quad 0,77174 ;$ a. Matriks solusi ideal positif $\left(\mathrm{P}^{\wedge}+\right)$ $0,77174 ; 0,77174 ; 0,77174 ; 0,77174)$

$$
P_{i}^{+}=\sqrt{\sum_{b=1}^{n}\left(K_{i b}-Z_{b}^{+}\right)^{2}}
$$




$$
\begin{aligned}
& P_{\mathrm{A} 1}=\sqrt{\begin{array}{c}
(0,77174-0,25725)^{2}+ \\
(1,11901-1,11901)^{2}+ \\
(0,27386-0,27386)^{2}+ \\
(1,13872-1,13872)^{2}+ \\
(0,67082-0,67082)^{2}
\end{array}} \\
& P_{\mathrm{A} 2}=\sqrt{\begin{array}{c}
(0,25725-0,25725)^{2}+ \\
(0,74600-1,11901)^{2}+ \\
(0,82158-0,27386)^{2}+ \\
(1,13872-1,13872)^{2}+ \\
(0,67082-0,67082)^{2}
\end{array}} \\
& =0,66267 \\
& P_{\mathrm{A} 3}=\sqrt{\begin{array}{c}
(0,25725-0,25725)^{2}+ \\
(1,11901-1,11901)^{2}+ \\
(0,82158-0,27386)^{2}+ \\
(1,13872-1,13872)^{2} \\
+(0,67082-0,67082)^{2}
\end{array}} \\
& =0,54772
\end{aligned}
$$$$
=0,51450
$$

b. Matriks solusi ideal negatif $\left(\mathrm{P}^{\wedge}{ }_{-}\right)$

$$
\begin{aligned}
P_{i}^{-}= & \sqrt{\sum_{b=1}^{n}\left(K_{i b}-Z_{b}^{-}\right)^{2}} \\
P_{\mathrm{A} 1}= & \sqrt{\begin{array}{l}
(0,77174-0,77174)^{2}+ \\
(1,11901-0,74600)^{2}+ \\
(0,27386-0,82158)^{2}+ \\
(1,13872-0,91097)^{2}+ \\
(0,67082-0,67082)^{2}
\end{array}} \\
= & 0,70071
\end{aligned}
$$

$$
P_{\mathrm{A} 2}=\sqrt{\begin{array}{c}
(0,25725-0,77174)^{2}+ \\
(0,74600-0,74600)^{2}+ \\
(0,82158-0,82158)^{2}+ \\
(1,13872-0,91097)^{2}+ \\
(0,67082-0,67082)^{2}
\end{array}}
$$$$
=0,56265
$$

$$
\begin{aligned}
P_{\mathrm{A} 3} & =\sqrt{\begin{array}{l}
(0,25725-0,77174)^{2}+ \\
(1,11901-0,74600)^{2}+ \\
(0,82158-0,82158)^{2}+ \\
(1,13872-0,91097)^{2}+ \\
(0,67082-0,67082)^{2}
\end{array}} \\
= & 0,67506
\end{aligned}
$$

Tabel 8. Nilai Separasi

\begin{tabular}{lll}
\hline Alternatif & Positif & \multicolumn{2}{c}{ Negatif } \\
\hline A01 & 0,51450 & 0,70071 \\
A02 & 0,66267 & 0,56265 \\
A03 & 0,54772 & 0,67506 \\
A04 & 0,63548 & 0,59318 \\
A05 & 0,37573 & 0,57634 \\
A06 & 0,66267 & 0,56265 \\
A07 & 0,69198 & 0,35618 \\
A08 & 0,67506 & 0,54772 \\
A09 & 0,63548 & 0,59318 \\
A10 & 0,75147 & 0,43703 \\
A11 & 0,69198 & 0,35618 \\
A12 & 0,71085 & 0,34357 \\
A13 & 0,71085 & 0,34357 \\
A14 & 0,83895 & 0,22774 \\
A15 & 0,71085 & 0,34357 \\
A16 & 0,83895 & 0,22774 \\
A17 & 0,69198 & 0,35618 \\
A18 & 0,75147 & 0,43703 \\
A19 & 0,51450 & 0,70071 \\
A20 & 0,78522 & 0,37300 \\
\hline
\end{tabular}

Setelah mendapatkan nilai separasi positif dan negatif, langkah selanjutnya menghitung keadaan relatif terhadap solusi ideal positif.

3.5 Menghitung keadaan relatif terhadap solusi ideal positif

Menentukan nilai preferensi untuk setiap alternatif dengan menggunakan :

$$
\begin{gathered}
U_{i}^{+}=\frac{C_{i}^{-}}{\left(C_{i}^{-}+C_{i}^{+}\right)} \\
=0,70071 /(0,70071+0,51450)=0,57662 \\
=0,56265 /(0,56265+0,66267)=0,45919
\end{gathered}
$$

\begin{tabular}{|c|c|c|c|}
\hline Rangkin & Alternatif & $\begin{array}{c}\text { Nilai } \\
\text { Preferensi }\end{array}$ & Keputusan \\
\hline 1 & $\mathrm{~A} 05$ & 0,60535 & Layak diterima \\
\hline 2 & A01 & 0,57662 & Layak diterima \\
\hline 3 & A19 & 0,57662 & Layak diterima \\
\hline 4 & A03 & 0,55207 & Layak diterima \\
\hline 5 & A04 & 0,48279 & Layak diterima \\
\hline 6 & A09 & 0,48279 & Layak diterima \\
\hline 7 & A06 & 0,45919 & Layak diterima \\
\hline 8 & $\mathrm{~A} 02$ & 0,45919 & Layak diterima \\
\hline 9 & A08 & 0,44793 & Layak diterima \\
\hline 10 & A10 & 0,36772 & Layak diterima \\
\hline 11 & A18 & 0,36772 & Layak diterima \\
\hline 12 & A17 & 0,33982 & Layak diterima \\
\hline 13 & A11 & 0,33982 & Layak diterima \\
\hline 14 & A07 & 0,33982 & Layak diterima \\
\hline 15 & A 15 & 0,32584 & Layak diterima \\
\hline 16 & A13 & 0,32584 & Layak diterima \\
\hline 17 & A12 & 0,32584 & Layak diterima \\
\hline 18 & A 20 & 0,32205 & Layak diterima \\
\hline
\end{tabular}

Tabel 9. Nilai preferensi untuk setiap alternative

\begin{tabular}{lrrr}
\hline Alternatif & \multicolumn{1}{c}{ Positif } & Negatif & Preferensi \\
\hline A01 & 0,51450 & 0,70071 & 0,57662 \\
A02 & 0,66267 & 0,56265 & 0,45919 \\
A03 & 0,54772 & 0,67506 & 0,55207 \\
A04 & 0,63548 & 0,59318 & 0,48279 \\
A05 & 0,37573 & 0,57634 & 0,60535 \\
A06 & 0,66267 & 0,56265 & 0,45919 \\
A07 & 0,69198 & 0,35618 & 0,33982 \\
A08 & 0,67506 & 0,54772 & 0,44793 \\
A09 & 0,63548 & 0,59318 & 0,48279 \\
A10 & 0,75147 & 0,43703 & 0,36772 \\
A11 & 0,69198 & 0,35618 & 0,33982 \\
A12 & 0,71085 & 0,34357 & 0,32584 \\
A13 & 0,71085 & 0,34357 & 0,32584 \\
A14 & 0,83895 & 0,22774 & 0,21350 \\
A15 & 0,71085 & 0,34357 & 0,32584 \\
A16 & 0,83895 & 0,22774 & 0,21350 \\
A17 & 0,69198 & 0,35618 & 0,33982 \\
A18 & 0,75147 & 0,43703 & 0,36772 \\
A19 & 0,51450 & 0,70071 & 0,57662 \\
A20 & 0,78522 & 0,37300 & 0,32205 \\
\hline
\end{tabular}

Hasil yang didapat solusi ideal positif yaitu prefensi akan digunakan sebagai alternatif perangkingan, yang nantinya hasil perangkingan akan menjadi acuan dalam menentukan layak tahu belum layaknya siswa menerima BKS SMK Negeri 3 Muko muko.

\subsection{Meranking alternatif}

Tahapan yang selanjutnya melakukan perangkingan dan menentukkan hasil keputusan dari tiap alternatif tersebut, maka diperoleh hasil :

Tabel 10. Keputusan Layak Diterima 
Setelah dilakukan rangking alternatif dapat ditentukan lah siswa yang layak dan tidak layak, dari hasil yang didapat 18 orang siswa layak menerima BKS sedangkan 2 orang siswa lagi belum layak menerima BKS

\section{Kesimpulan}

Setelah dianalisis menggunakan SPK BKS menggunakan metode Topsis, maka sistem dapat menentukan layak atau tidaknya siswa menerima BKS secara tepat. Sistem ini dapat membantu menentukan kelayakan siswa penerima bantuan diseleksi dengan cepat dan dapat meringankan pekerjaan petugas dalam menentukan layak atau tidaknya penerima BKS.

\section{Daftar Rujukan}

[1] Febrian, T. B., \& Simangunsong, A. (2020). Decision Support System Employee Performance Appraisal Method Using TOPSIS. Journal Of Computer Networks, Architecture and High Performance Computing, 2(2), 307-312. DOI: https://doi.org/10.47709/cnapc.v2i2.412 .

[2] Putri, R. P., Ilayaraja, M., Shankar, K., Hashim, W., Odarich, I. N., Maseleno, A. (2019). Decision Support System for Exemplary Teacher Selection in Elementary School using Topsis Method. International Journal of Engineering and Advanced Technology, 9(1), 120-128. https://doi.org/10.35940/ijeat.a1103.1291s419.

[3] Balioti, V., Tzimopoulos, C., \& Evangelides, C. (2018). MultiCriteria Decision Making Using TOPSIS Method Under Fuzzy Environment. Application in Spillway Selection. Proceedings, 2(11). DOI: https://doi.org/10.3390/proceedings2110637

[4] Kusakci, A. O. (2019). A Decision Support System For Product Selection Using Hybridized Fuzzy-AHP TOPSIS Methods. Uluslararasi Muhendislik Arastirma Ve Gelistirme Dergisi, 99 108. DOI: https://doi.org/10.29137/umagd.370349

[5] Trisna, N., Rahman, S. N., \& Jamhur, A. I. (2019). Sistem Pendukung Keputusan Penerima Beasiswa dengan Metode Technique For Order of Preference By Similarity To Ideal Solution (TOPSIS). JURNAL INFORMATIKA, 7(3), 126-132. DOI: https://doi.org/10.36987/informatika.v7i3.1383 .

[6] Do Carmo Silva, M., Gomes, C. F., \& Da Costa Junior, C. L. (2019). The use of TOPSIS for Ranking WIPO'S Innovation Indicators. Innovar, 29(73), 133-148. DOI: https://doi.org/10.15446/innovar.v29n73.78027 .

[7] Wen, K., \& You, M. (2018). The Cardinal TOPSIS via Grey Relational Grade. The Second International Conference on Materials Chemistry and Environmental Protection, 1. DOI: https://doi.org/10.5220/0008189002930296 .
[8] Su, L., Li, H., Cao, Y., \& Lv, L. (2019). Project Delivery System Decision Making using Pythagorean Fuzzy TOPSIS. Engineering Economics, 30(4), 461-471. DOI: https://doi.org/10.5755/j01.ee.30.4.22041 .

[9] Wang, V. V., Sukamto, A. S., \& Pratama, E. E. (2019). Sistem Pendukung Keputusan Seleksi Mahasiswa Penerima Beasiswa BBP-PPA dengan Metode TOPSIS pada Fakultas Teknik UNTAN. Jurnal Sistem dan Teknologi Informasi (JUSTIN), 7(2). DOI: https://doi.org/10.26418/justin.v7i2.29656 .

[10] Sari, R. (2018). Sistem Pendukung Keputusan Pemilihan Siswa Penerima Beasiswa dengan Metode Topsis. Evolusi: Jurnal Sains dan Manajemen, 6(2). DOI: https://doi.org/10.31294/evolusi.v6i2.4426 .

[11] Tuslaela, T. (2020). The Scholarship Awarding Decision Support System Uses The Topsis Method. Jurnal Riset Informatika, 2(4), 201-206. DOI: https://doi.org/10.34288/jri.v2i4.154 .

[12]Zamdial, Z., Hartono, D., Bakhtiar, D., \& Nofridiansyah, E. (2017). Studi Identifikasi Kerusakan Wilayah Pesisir Di Kabupaten Mukomuko Provinsi Bengkulu. Jurnal Enggano, 2(2), 196-207. DOI: https://doi.org/10.31186/jenggano.2.2.196207 .

[13] Irvanizam, I. (2018). Application of the Fuzzy Topsis MultiAttribute Decision Making Method to Determine Scholarship Recipients. Journal of Physics: Conference Series, 978. DOI: https://doi.org/10.1088/1742-6596/978/1/012056 .

[14] Kemdikbud. (2017). Mendikbud: Revitalisasi Fungsi dan Peran Komite Sekolah berazaskan Gotong Royong [online] (16 Januari 2017) Available at: https://www.kemdikbud.go.id/main/blog/2017/01/mendikbudrevitalisasi-fungsi-dan-peran-komite-sekolah-berazaskan-gotongroyong. [Accessed 29 November 2020].

[15] Astarina, M., \& Asnafiyah, A. (2019). Keterlibatan Masyarakat dalam Pengembangan Mutu Madrasah: Studi Program Komite di MIN 1 Bantul Yogyakarta. Jurnal Isema : Islamic Educational Management, 4(2), 181-192. DOI: https://doi.org/10.15575/isema.v4i2.6535.

[16]Aktavera, B., Defit, S., \& Sumijan, S. (2020). Sistem Penunjang Keputusan dalam Penentuan Prioritas Pembangunan Menggunakan Metode Trus Base dengan Topsis. Jurnal $\begin{array}{llll}\text { Informatika Ekonomi Bisnis, 2(4). DOI: } & \end{array}$ https://doi.org/10.37034/infeb.v2i4.76 .

[17] Andrianof, H. (2019). Sistem Pendukung Keputusan Penerima Beasiswa Pada Smp Negeri 2 Padang dengan Metode Technique For Order of Preference By Similarity to Ideal Solution (Topsis) Menggunakan Bahasa Pemograman PHP dan Database MySQL. Jurnal KomtekInfo, 5(3), 20-32. DOI: https://doi.org/10.29165/komtekinfo.v5i3.145 . 